\title{
EXPENDITURE-BASED SEGMENTATION OF VISITORS TO THE TSITSIKAMMA NATIONAL PARK
}

\author{
Martinette Kruger: North-West University \\ Melville Saayman: North-West University \\ Andrea Saayman: North-West University
}

\section{SYNOPSIS}

Purpose and/or objectives: The purpose of this article is to apply expenditure-based segmentation to visitors at the Tsitsikamma National Park. The objective of the research is twofold, to identify the socio-demographic and behavioural variables that influence spending at the Tsitsikamma National Park and to make recommendations on how to attract the high-spending market.

Problem investigated: The Tsitsikamma National Park is Africa's oldest and largest marine reserve and plays a vital role in the preservation and conservation of marine fauna and flora. The park is also a popular holiday destination for international and local tourists and therefore plays an important role in the regional economy. Due to the importance of the park to the community and region, the Tsitsikamma National Park needs to attract more high spenders since this will contribute to the sustainability of the park. Expenditure-based segmentation is regarded as the best method for creating a profile of the high-spending market.

Design and/or methodology and/or approach: To achieve this, tourist surveys from 2001 to 2008 were used. In total, 593 questionnaires were used in the analysis. Statistical analysis was done by applying K-means clustering and Pearson's chisquare as well as ANOVA analysis.

Findings and/or implications: The research revealed that the province of origin, group size, length of stay and accommodation preference have a positive influence on higher spending.

Originality and/or value of the research: Even though this type of research has been done for the Kruger National Park, a more innovative approach was followed by using K-means clustering, which is also the first time that this approach was used in determining the high-spending market at the Tsitsikamma National Park.

Conclusion: Two distinct markets were identified. These were the high and low spenders where the most significant differences were with regard to province of origin, group size, length of stay and preferred type of accommodation. Interestingly, aspects such as owning a Wild Card (which is a loyalty card) showed no significant difference. The same applied for age, marital status or frequency of visits. Therefore, the results (if one compares this research with that done at the Kruger National Park) confirm that the size of operations and activities available have a dual impact.

Key words: Tsitsikamma National Park; Expenditure-based segmentation; Market segmentation

\section{INTRODUCTION}

The Tsitsikamma National Park is situated in the heart of the picturesque tourist region known as the Garden Route, found in the Eastern Cape Province of South Africa. The park stretches for $80 \mathrm{~km}$ from the Krom River Forest Station to the Salt River and it lies between the Tsitsikamma Mountains and the coast. When the park was proclaimed in September 1964, it became the first marine national park to be proclaimed in Africa (SANParks, 2008). The Tsitsikamma National Park protects a variety of inter-tidal and marine life forms. The park is one of the largest Marine Protected Areas (MPAs) in the world, conserving $11 \%$ of South Africa's Temperate South Coast rocky shoreline. Approximately $30 \%$ of the park is covered in fynbos (Cape Floral Kingdom) scattered among the forest vegetation, boasting a wide variety of beautiful flowers, including proteas and heaths. Dolphins and many species of sea birds are also present, including the southern right whale (SANParks, 2008). The park furthermore provides various tourism activities such as hiking, backpacking, boating tours, swimming, picnicking and eating at the 
restaurant, purchasing of souvenirs, photography and appreciation of nature to name but a few (SANParks, 2008).

National parks in South Africa have three distinct purposes. Firstly, the conservation of a representative sample of the biodiversity of the country. Secondly, to provide a recreation outlet where the wonders of the park can be experienced and enjoyed. Thirdly, to maintain a relationship of community upliftment and capacity building among people living in and around the parks. Based onthis, national parks have to create an environment from which the communities can benefit whilst, at the same time, conserving the natural environment. With this in mind, according to Kastenholz (2005:556) and WTO (2002:2), an increase in tourist spending creates a greater socio-economic impact. It is therefore imperative to identify the high-spending market. With more that 20 national parks in South Africa (SANParks, 2008), This is especially important from a sustainability point of view. The purpose of this article is to apply expenditurebased segmentation to visitors at the Tsitsikamma National Park. According to Spotts and Mahoney (1991:24), segmenting travel markets on the basis of travel expenditure is a useful alternative to the more common approach of segmenting on the basis of travel activity when some type of volume segmentation is desired. This is because travel (park) marketers/managers seek visitors who will spend money, and not just time, on their tourism (national park) products (Mok \& Iverson, 2000:299). In terms of managerial implications, expenditure is considered to be an important factor that helps to understand the consumption behaviour of tourists. This enables tourism (park) marketers/managers to develop appropriate products and to evaluate the economic benefits of each segment through activity segmentation (Legohérel \& Wong, 2006:16).

To achieve the purpose, the article is structured in the following manner: the problem under investigation will be discussed, followed by a description of the method of research. This is followed by a discussion of the results. Implications are discussed and, finally, recommendations and concluding remarks are made.

\section{PROBLEM STATEMENT}

According to Statistics South Africa's 2009 Annual Report, the Eastern Cape Province is one of the poorest provinces in South Africa (StatsSA, 2009). With this in mind, Wade and Eagles (2003:196) pointed out that national parks, such as the Tsitsikamma National Park, can contribute to a significant proportion of the national GDP, foreign exchange earnings and employment figures. Oberholzer, Saayman, Saayman and Slabbert (2009:192) proved this in their study of the socio-economic impact of the Tsitsikamma National Park, where results showed that the total impact of the park on the local economy amounts to over R21 million. The region is very reliant on tourism - approximately $46.7 \%$ of employment opportunities in the area are a direct result of the park (Oberholzer et al., 2009:193). The Tsitsikamma National Park attracts tourists to the region, provides economic opportunities for local entrepreneurs, acts as an implementing agency for poverty relief programmes, and creates employment and training opportunities for some of the area's poverty-stricken communities (Faasen, 2006:10). The park therefore makes an invaluable contribution to the economic development of the surrounding communities, the region and the Eastern Cape Province.

The problem facing SANParks and the Tsitsikamma National Park, which is the premise of this research, is that, with decreasing levels of public funding, the Tsitsikamma National Park is largely dependent on internal capital generated by tourism and visitors to the park (Wade \& Eagles, 2003:196). Due to the importance of the park in terms of economic growth and job creation in the region, the Tsitsikamma National Park has to identify the market that provides the greatest return on investment (i.e. the highspending market) at the park. This will enable the generation of enough capital to continue to create a favourable tourist destination while, at the same time, conserving the natural environment (Tonge \& Moore, 2007:768). The problem under investigation is based on the questions: Who are the highspending tourists visiting Tsitsikamma National Park? and which socio-demographic and behavioural variables influence spending at the park? Since the process of market segmentation groups visitors/tourists that share similar needs and buying characteristics together (Dibb \& Simkin, 1996:1), identifying the high-spending market can be done through the process of market segmentation (Mykletun, Crotts \& Mykletun, 2001:494). 
More specifically, expenditure-based segmentation needs to be applied since this method of segmentation divides visitors into spending market segments, for example low, medium and highspending segments, and provides a complete profile of each of the markets as well as the determinants that positively influence higher spending (Kruger, 2009:53). This method of segmentation is supported by Diaz-Perez, Bethencourt-Cejas and Alvarez-Gonzales (2005:961), Saayman, Van der Merwe and Pienaar (2008:18) and Legohérel and Wong (2006:16) who indicated that visitor expenditure is an important factor for comprehensive tourism segmentation. The results from such segmentation therefore distinguish the high spenders from other segments in terms of socio-demographic and behavioural characteristics such as age, group size, length of stay, trip purpose, travel mode and their expenditure patterns (Mok \& Iverson, 2000:299; Spotts \& Mahoney, 1991:24). Since correlations between these different socio-demographic and behavioural characteristics (determinants) can be made, this information can be used by park management to enhance the economic benefits by increasing visitor spending and contributing to aspects such as a longer length of stay.

Laesser and Crouch (2006:397), argue that the underlying rationale of segmenting markets by means of expenditure is based on the necessity of improving the effectiveness and efficiency of marketing programmes and their resources, both in terms of addressing (1) the right group of tourists and (2) their relevant needs. Tourist spending is one of the most critical variables of analysis for tourist destinations, since it directly determines the tourism sector's profitability (Frechtling, 2006:1). It is therefore important to determine which visitors spend most at the Tsitsikamma National Park and which variables are most influential in determining their expenditure levels (Kastenholz, 2005:557). According to Gokovali, Bahar and Kozak (2007:737), once the factors that affect visitor expenditure are determined, policy development will be possible to increase the spending to maximise economic benefits of the park. Park management can thus effectively apply the determinants when doing market segmentation to focus their marketing efforts on those visitors who spend the most at the park (Kruger, 2009:16).

With the above-mentioned benefits in mind, the Tsitsikamma National Park will benefit greatly from identifying the high-spending market at the park through expenditure-based segmentation. From a sustainability point of view, this is especially important since increased visitor spending greatly contributes to the successful execution of the three distinct purposes of national parks in South Africa. However, Spotts and Mahoney (1991:24) point out that travel expenditures for a given unit of travel activity vary significantly from one travel party to the next. Thus, two types of travellers who spend a vacation in the same area and at the same time spend their money in very different ways. Saayman, Saayman and Naudé (2000:10) support this view and found in their research on tourists visiting South Africa that different markets (tourists from different countries) have different spending patterns and, from their study, a distinction between high- and low-spending foreign markets could be made. With this in mind, it is important to take the results of previous research conducted specifically at nature-based destinations into consideration. This will be discussed in the next section.

Spotts and Mahoney (1991:24) divided visitors into light, medium and high spenders based on each visitor's total expenditure in the region. Heavy spenders were distinguished from other segments based on their larger group sizes (also prone to travel with children) and longer length of stay as well as greater involvement with recreation and visitation to attractions. Leones, Colby and Crandall (1998:63-64) revealed that nature tourists spend more per party trip than other visitors in the same area. The number of local attractions visited, shorter trip duration and place of residence also had a positive effect on tourist spending.

In their study of tourist expenditure in the North York Moors National Park (UK), Downward and Lumsdon (2004:419) found that mode of travel influenced spending patterns. Car-borne visitors were more likely to spend more per group and stay significantly longer than visitors travelling with public transport, for example buses. Pouta, Neuvonen and Sievänen (2006:118), who studied the determinants of nature trip expenditures in Southern Finland, found that increased visitor expenditures were related to trip characteristics such as higher income, first-time visits, longer distances travelled and longer lengths of stay. Saayman, Van der Merwe and Pienaar (2007:17) found similar results and made a distinction between high, medium and low spenders in their study of visitors to the Kruger National Park (South Africa). Visitors who stayed longer, travelled in smaller groups and who had travelled further to reach the 
park were likely to spend more. Saayman et al. (2008:14) also found in a study of biltong hunters in South Africa, that age, a higher income, length of stay, specialisation and the location of the hunting destination were associated with higher spending. By means of logistic regression analysis, Mehmetoglu (2007:213) found that travel activities were a reliable predictor of tourist spending behaviour. Results revealed that visitors, who consider nature-based activities as important, tend to be high spenders. Socio-demographic variables such as age, household income, length of stay and trip purpose were also positively associated with higher daily expenditures.

Being South Africa's oldest marine national park, the Tsitsikamma National Park offers a unique tourism experience and, based on the varying results of previous research discussed above, it can be assumed that characteristics and spending behaviour of the visitors, including the high-spending market, will also differ. Therefore, the purpose of this research to segment visitors at the Tsitsikamma National Park based on their expenditure with the objective of (i) identifying the socio-demographic and behavioural variables that distinguish the high-spending market at the park and (ii) making recommendations on how to attract these markets to the park. The results obtained from this research will greatly assist park management in determining ways that the park can not only attract more high spenders but also encourage overall visitor expenditure. The latter is especially important for the surrounding communities and region, due to the high levels of unemployment in the Eastern Cape Province (StatsSA, 2009:viii). Additionally, based on the literature review, this is only the second time that expenditure-based segmentation will be applied to a national park in South Africa. The results of this research will therefore not only contribute to the literature base concerning the high-spending market at national parks in South Africa but will also prove to be extremely beneficial for the parks from a marketing, economic and especially a sustainability point of view.

\section{METHOD OF RESEARCH}

The research is a quantitative study conducted by means of a structured questionnaire since one needs to collate individual spending and socio-demographic data to apply segmentation successfully. The study applies structural data analysis to identify segments as well as hypothesis testing to explore the differences between the identified segments, as is standard in market segmentation studies. As such, the research is exploratory and causal in nature. Surveys were conducted at the Tsitsikamma National Park over a period of eight years (2001 to 2008), and the method of research used will be discussed under the following headings: (i) the research instrument, (ii) sampling, (iii) the research technique and (iv) the statistical analysis.

\section{Research Instrument}

The questionnaire used to survey visitors to the Tsitsikamma National Park remained similar throughout the period of data collection (2001 - 2008) and consisted of three sections. In Section A, demographic details (home language, marital status, age and province of origin) were surveyed, while section B focused on spending behaviour (number of persons paid for, frequency of visits, length of stay and amount spent) and travel motivational factors. The travel motivations were based on the work of (Crompton 1979), but were adapted for national parks. Section $C$ of the questionnaire consisted of more detailed information about the visitors' general behaviour (type of magazines/newspapers they read and their catering preferences, for example). For the purposes of this article, the information obtained from Sections A and B was predominantly used since these sections in the questionnaire captured visitors' socio-demographic and behavioural information needed to conduct the analysis, as described in Table 1. Table 1 also shows that most questions in the included sections of the questionnaire had an assigned number to the chosen answer, which was then used in the analysis. 
Table 1: Questions used and their descriptions

\begin{tabular}{|c|c|c|c|}
\hline Category & Question description & Coding & Variable \\
\hline Socio-demographic & $\begin{array}{l}\text { Home language } \\
\text { Age } \\
\\
\text { Marital status } \\
\text { Country of residence } \\
\text { Province of residence } \\
\text { Gauteng } \\
\text { Western Cape } \\
\text { Level of education } \\
\text { No school } \\
\text { Matric } \\
\text { Diploma, Degree } \\
\text { Post Graduate } \\
\text { Professional }\end{array}$ & $\begin{array}{c}\text { English=1; } \text { Afrikaans }=2 ; \text { Other }=3 \\
>19 \text { years } \\
20-24 \text { years } \\
25-34 \text { years } \\
35-49 \text { years } \\
50-64 \text { years } \\
65+\text { years } \\
\text { Married }=1 ; \text { Other }=0 \\
\text { Foreign country }=1 ; \mathrm{RSA}=0 \\
\\
\text { Yes }=1 ; \mathrm{No}=0 \\
\text { Yes }=1 ; \mathrm{No}=0 \\
\\
\text { Yes }=1 ; \mathrm{No}=0 \\
\text { Yes }=1 ; \mathrm{No}=0 \\
\text { Yes }=1 ; \mathrm{No}=0 \\
\text { Yes }=1 ; \mathrm{No}=0 \\
\mathrm{Yes}=1 ; \mathrm{No}=0\end{array}$ & $\begin{array}{c}\text { Language } \\
\text { Age } 1 \\
\text { Age } 2 \\
\text { Age } 3 \\
\text { Age } 4 \\
\text { Age } 5 \\
\text { Age } 6 \\
\text { Marital status } \\
\text { Foreign } \\
\text { Gauteng } \\
\text { Western Cape } \\
\text { edu } 1 \\
\text { edu } 2 \\
\text { edu } 3 \\
\text { edu } 4 \\
\text { edu } 5\end{array}$ \\
\hline Behavioural & $\begin{array}{l}\text { Group size } \\
\text { Number of visits to park } \\
\text { Number of days } \\
\text { Preferred } \\
\text { accommodation } \\
\text { Camping } \\
\text { Chalets } \\
\text { Huts } \\
\text { Tented camps } \\
\text { Guest house } \\
\text { Wilderness camp } \\
\text { Wild Card holder }\end{array}$ & $\begin{array}{l}\text { Open question } \\
\text { Open question } \\
\text { Open question } \\
\text { Yes }=1 ; \mathrm{No}=0 \\
\text { Yes }=1 ; \mathrm{No}=0 \\
\text { Yes }=1 ; \mathrm{No}=0 \\
\mathrm{Yes}=1 ; \mathrm{No}=0 \\
\mathrm{Yes}=1 ; \mathrm{No}=0 \\
\mathrm{Yes}=1 ; \mathrm{No}=0 \\
\mathrm{Yes}=1 ; \mathrm{No}=0\end{array}$ & $\begin{array}{c}\text { Group size } \\
\text { Times visited } \\
\text { Days spent } \\
\\
\text { Camping } \\
\text { Chalets } \\
\text { Huts } \\
\text { Tent camp } \\
\text { Guest house } \\
\text { Wilderness } \\
\text { camp } \\
\text { Wild Card } \\
\end{array}$ \\
\hline
\end{tabular}

\section{Sampling}

Since 2001, surveys were conducted annually at the Tsitsikamma National Park and, in 2007, a winter and a summer survey were conducted. The sample sizes are indicated in Table 2. All overnight visitors in the park during the time of the survey formed part of the sample, hence convenience or availability sampling was used. Note that the definition of a tourist was applied for the purpose of the research and therefore only overnight visitors were considered in the surveys. Overnight visitors furthermore make use of more facilities and activities during their stay, and thus spend more. Both overnight visitors staying in chalets and the camping area were included in the surveys.

\section{Research Technique}

Field workers distributed questionnaires in the evenings and collected the questionnaires later during the evenings and/or early mornings. In total, 829 questionnaires were administrated for the Tsitsikamma National Park over a period of nine years. According to Saayman, Fouché and Kruger (2008) the profile of visitors has remained similar for this park since 2001. Hence, it is believed that the sampling is representative of the total population. 
Table 2: Total number of questionnaires completed for Tsitsikamma National Park (2001. 2008)

\begin{tabular}{|l|c|c|c|c|c|c|c|c|c|}
\hline \multicolumn{1}{|c|}{ YEAR } & 2001 & 2002 & 2003 & 2004 & 2005 & 2006 & 2007 & 2007 & 2008 \\
\hline $\begin{array}{l}\text { Survey } \\
\text { month }\end{array}$ & May & July & $\begin{array}{c}\text { Decemb } \\
\text { er }\end{array}$ & $\begin{array}{c}\text { Novemb } \\
\text { er/Dece } \\
\text { mber }\end{array}$ & $\begin{array}{c}\text { Novemb } \\
\text { er/Dece } \\
\text { mber }\end{array}$ & July & $\begin{array}{c}\text { June/Jul } \\
y\end{array}$ & December & $\begin{array}{c}\text { Marc } \\
\mathrm{h}\end{array}$ \\
\hline $\begin{array}{l}\text { Number of } \\
\text { questionnai } \\
\text { res }\end{array}$ & 73 & 48 & 122 & 91 & 83 & 64 & 41 & 151 & 156 \\
\hline
\end{tabular}

\section{Statistical analysis}

Microsoft ${ }^{\odot}$ Excel $^{\odot}$ was used for data capturing and basic data analysis while SPSS (SPSS Inc, 2007) was used for the analysis of data. The statistical analysis consisted of three stages. Firstly, all the data $(N=829)$ was pooled and expenditure was deflated with the consumer price index to render real expenditure, which is comparable across different years. All respondents who did not complete the spending information were disregarded and this resulted in a dataset with 593 members. In addition, the total expenditure was divided by the number of people for which the respondent is financially responsible, and the number of days spent in the park. The result was a real expenditure per person per day variable, which was used to segment the data. Secondly, to divide the data into expenditure segments, this research did not take an a priori view of which data points should fall into which segment. Rather, the natural structure of the data was explored, using cluster analysis. In cluster analysis, grouping is done based on similarities or dissimilarities and requires a similarity measure from which these similarities can be computed. In many cases, these similarity measures are a distance measure (Johnson \& Wichern, 2002:671-678). One method of clustering is K-means clustering. With K-means clustering, the data is divided into $\mathrm{K}$ initial clusters, where $\mathrm{K}$ is chosen by the researcher. Each item is assigned to a cluster based on distances to the mean value of the cluster. The distance measure used is the Euclidean distance (Johnson \& Wichern, 2002:696). Other researchers (see Mok and Iverson (2000) and Saayman et al. (2008)) often use three expenditure segments, high, medium and low. Therefore, $\mathrm{K}$ was chosen as three groups in the analysis and clustering was done using SPSS. Thirdly, once the segments were identified, factors (as tested by the questionnaire outlined in Table 1) were explored using Chi-square and ANOVA analyses.

\section{ANALYSIS AND FINDINGS}

Using $\mathrm{K}$-means clustering and setting $\mathrm{K}$ at 3 , real expenditure per person per day was divided into three clusters. However, in the third cluster, there was only one member, clearly indicating an outlier. Therefore, the remaining two clusters were used for further analysis. The cluster means and number of items in each cluster are shown in Table 3 below.

Table 3: Cluster Centres and members

\begin{tabular}{|l|r|r|r|}
\hline & \multicolumn{3}{|c|}{ Cluster } \\
& \multicolumn{1}{|c|}{1} & \multicolumn{1}{c|}{2} & \multicolumn{1}{c|}{3} \\
\hline Mean & 1158.51 & 335.07 & 7052.24 \\
\hline $\begin{array}{l}\text { Number of } \\
\text { cases }\end{array}$ & 122 & 470 & 1 \\
\hline
\end{tabular}

It is therefore evident that there are only two clearly-defined segments in the data. These are a highspending segment (cluster 1) and a low-spending segment (cluster 2). The average spending per person per day in the high-spending segment is R1158.51, while the average for the low-spending segment is R335.07. There are also more members in the low-spending segment than in the high-spending segment. 
Table 4 provides an overview of the descriptive results of the two clusters with regard to all the characteristics and behavioural variables tested in the questionnaire, as well as Pearson's Chi-square statistic to test the difference between the clusters.

Table 4: Chi-square results

\begin{tabular}{|c|c|c|c|c|c|c|}
\hline \multicolumn{2}{|l|}{ Variable } & \multicolumn{3}{|c|}{ Cluster Number } & \multirow{2}{*}{$\begin{array}{c}\text { Pearson's } \\
\chi^{2}\end{array}$} & \multirow[b]{2}{*}{ Significance } \\
\hline & & 2 & 1 & Total & & \\
\hline \multirow[t]{3}{*}{ Lang } & 0 & 291 & 84 & 375 & \multirow[t]{3}{*}{1.718} & \multirow[t]{3}{*}{0.19} \\
\hline & 1 & 175 & 38 & 213 & & \\
\hline & Total & 466 & 122 & 588 & & \\
\hline \multirow[t]{3}{*}{ Age1 } & 0 & 457 & 121 & 578 & \multirow[t]{3}{*}{0.341} & \multirow[t]{3}{*}{0.56} \\
\hline & 1 & 7 & 1 & 8 & & \\
\hline & Total & 464 & 122 & 586 & & \\
\hline \multirow[t]{3}{*}{ Age2 } & 0 & 436 & 117 & 553 & \multirow[t]{3}{*}{0.681} & \multirow[t]{3}{*}{0.409} \\
\hline & 1 & 28 & 5 & 33 & & \\
\hline & Total & 464 & 122 & 586 & & \\
\hline \multirow[t]{3}{*}{ Age3 } & 0 & 382 & 95 & 477 & \multirow[t]{3}{*}{1.268} & \multirow[t]{3}{*}{0.26} \\
\hline & 1 & 82 & 27 & 109 & & \\
\hline & Total & 464 & 122 & 586 & & \\
\hline \multirow[t]{3}{*}{ Age4 } & 0 & 232 & 70 & 302 & \multirow[t]{3}{*}{2.105} & \multirow[t]{3}{*}{0.147} \\
\hline & 1 & 232 & 52 & 284 & & \\
\hline & Total & 464 & 122 & 586 & & \\
\hline \multirow[t]{3}{*}{ Age5 } & 0 & 379 & 91 & 470 & \multirow[t]{3}{*}{3.059} & \multirow[t]{3}{*}{$0.080^{*}$} \\
\hline & 1 & 85 & 31 & 116 & & \\
\hline & Total & 464 & 122 & 586 & & \\
\hline \multirow[t]{3}{*}{ Age6 } & 0 & 434 & 116 & 550 & \multirow[t]{3}{*}{0.401} & \multirow[t]{3}{*}{0.526} \\
\hline & 1 & 30 & 6 & 36 & & \\
\hline & Total & 464 & 122 & 586 & & \\
\hline \multirow[t]{3}{*}{ Marry } & 0 & 126 & 32 & 158 & \multirow[t]{3}{*}{0.02} & 0.888 \\
\hline & 1 & 343 & 90 & 433 & & \\
\hline & Total & 469 & 122 & 591 & & \\
\hline Foreign & 0 & 406 & 98 & 504 & 3.64 & $0.056^{*}$ \\
\hline & 1 & 57 & 23 & 80 & & \\
\hline & Total & 463 & 121 & 584 & & \\
\hline Gauteng & 0 & 305 & 62 & 367 & 8.013 & $0.005^{\star \star}$ \\
\hline & 1 & 153 & 56 & 209 & & \\
\hline & Total & 458 & 118 & 576 & & \\
\hline Western Cape & 0 & 327 & 104 & 431 & 13.955 & $<0.001^{* *}$ \\
\hline & 1 & 131 & 14 & 145 & & \\
\hline & Total & 458 & 118 & 576 & & \\
\hline edu1 & 0 & 468 & 119 & 587 & 3.907 & $0.048^{* \star}$ \\
\hline & 1 & & 1 & 1 & & \\
\hline
\end{tabular}




\begin{tabular}{|c|c|c|c|c|c|c|}
\hline & Total & 468 & 120 & 588 & & \\
\hline \multirow[t]{3}{*}{ edu2 } & 0 & 397 & 96 & 493 & \multirow[t]{3}{*}{1.644} & \multirow[t]{3}{*}{0.2} \\
\hline & 1 & 71 & 24 & 95 & & \\
\hline & Total & 468 & 120 & 588 & & \\
\hline \multirow[t]{3}{*}{ edu3 } & 0 & 290 & 73 & 363 & \multirow[t]{3}{*}{0.052} & \multirow[t]{3}{*}{0.82} \\
\hline & 1 & 178 & 47 & 225 & & \\
\hline & Total & 468 & 120 & 588 & & \\
\hline \multirow[t]{3}{*}{ edu4 } & 0 & 357 & 95 & 452 & \multirow[t]{3}{*}{0.447} & \multirow[t]{3}{*}{0.504} \\
\hline & 1 & 111 & 25 & 136 & & \\
\hline & Total & 468 & 120 & 588 & & \\
\hline \multirow[t]{3}{*}{ edu5 } & 0 & 375 & 100 & 475 & \multirow[t]{3}{*}{0.827} & \multirow[t]{3}{*}{0.661} \\
\hline & 1 & 92 & 20 & 112 & & \\
\hline & Total & 467 & 120 & 587 & & \\
\hline \multirow[t]{3}{*}{ Camping } & 0 & 122 & 65 & 187 & \multirow[t]{3}{*}{20.594} & \multirow[t]{3}{*}{$<0.001^{* *}$} \\
\hline & 1 & 167 & 29 & 196 & & \\
\hline & Total & 289 & 94 & 383 & & \\
\hline \multirow[t]{3}{*}{ Chalets } & 0 & 162 & 34 & 196 & \multirow[t]{3}{*}{11.225} & \multirow[t]{3}{*}{$0.001^{* \star}$} \\
\hline & 1 & 127 & 60 & 187 & & \\
\hline & Total & 289 & 94 & 383 & & \\
\hline \multirow[t]{3}{*}{ Huts } & 0 & 207 & 64 & 271 & \multirow[t]{3}{*}{0.43} & \multirow[t]{3}{*}{0.512} \\
\hline & 1 & 82 & 30 & 112 & & \\
\hline & Total & 289 & 94 & 383 & & \\
\hline \multirow[t]{3}{*}{ Tented camp } & 0 & 264 & 80 & 344 & \multirow[t]{3}{*}{3.023} & \multirow[t]{3}{*}{$0.082^{*}$} \\
\hline & 1 & 25 & 14 & 39 & & \\
\hline & Total & 289 & 94 & 383 & & \\
\hline \multirow[t]{3}{*}{ Guesthouse } & 0 & 266 & 89 & 355 & \multirow[t]{3}{*}{0.729} & \multirow[t]{3}{*}{0.393} \\
\hline & 1 & 23 & 5 & 28 & & \\
\hline & Total & 289 & 94 & 383 & & \\
\hline \multirow[t]{3}{*}{ Wilderness camp } & 0 & 252 & 83 & 335 & \multirow[t]{3}{*}{0.078} & 0.779 \\
\hline & 1 & 37 & 11 & 48 & & \\
\hline & Total & 289 & 94 & 383 & & \\
\hline Wild card & 0 & 84 & 21 & 105 & 0.939 & 0.333 \\
\hline & 1 & 160 & 53 & 213 & & \\
\hline & Total & 244 & 74 & 318 & & \\
\hline
\end{tabular}

** indicates significance at a $5 \%$ level, ${ }^{*}$ indicates significance at a $10 \%$ level.

In terms of the continuous variables, an ANOVA was conducted and the results are indicated in Table 5. The average group size for cluster 1 is 1.46 persons, while cluster 2 has a mean group size of 2.07 persons. In terms of previous visits, cluster 1 has visited the park 2.31 times on average, while the mean value for cluster 2 is 2.18 . Cluster 1 tends to spend an average of 3.3 days at the park, while cluster 2 only spends 2.57 days. 
Table 5: ANOVA results

\begin{tabular}{|ll|r|r|r|r|r|}
\hline & & \multicolumn{1}{c|}{$\begin{array}{c}\text { Sum of } \\
\text { squares }\end{array}$} & \multicolumn{1}{c|}{ df } & \multicolumn{1}{c|}{$\begin{array}{c}\text { Mean } \\
\text { square }\end{array}$} & \multicolumn{1}{c|}{ F } & Significance \\
\hline Group size & Between groups & 7.874 & 1 & 7.874 & 13.269 & $<0.001^{* *}$ \\
& Within groups & 115.121 & 194 & 0.593 & & \\
& Total & 122.995 & 195 & & & \\
\hline Times visited & Between groups & 1.611 & 1 & 1.611 & 2.474 & 0.116 \\
& Within groups & 357.623 & 549 & 0.651 & & \\
& Total & 359.234 & 550 & & & \\
\hline Days spent & Between groups & 49.983 & 1 & 49.983 & 25.389 & $<0.001^{* *}$ \\
& Within groups & 1122.136 & 570 & 1.969 & & \\
& Total & 1172.119 & 571 & & & \\
\hline
\end{tabular}

** indicates significance at a $5 \%$ level.

It can be seen from Tables 4 and 5 that the only significant differences between the high- and lowspending groups are to be found in the residing province of the respondent, the level of education of respondents, group size, the time spent at the park and the preference for camping relative to chalets.

The results therefore indicate that visitors from Gauteng fall in the high-spending category, while visitors from the Western Cape fall predominantly in the low-spending cluster. These two markets are some of the main markets for the Tsitsikamma National Park. The level of education of respondents also indicates significant differences at a $10 \%$ level of significance. When this is explored further (refer to edu1, edu2, edu3 etc. in Table 4 above), the difference lies in the first and lowest level of education, namely no formal schooling. Interestingly, some respondents in the high-spending cluster fall into this education category, but none of the low-spending cluster. If the average results of the clusters are compared for other higher levels of education, it seems as if there is no clear pattern and therefore the level of education does not seem to have a very significant influence on distinguishing low-spenders from high-spenders.

Furthermore, the results indicate that high-spenders travel in smallergroups (1.46 versus 2.07) and spend more days at the park (3.3 versus 2.57 for low-spenders). The low-spending cluster has a clear preference for camping, which is relatively cheaper than most other forms of accommodation, while the high-spending cluster prefers staying in chalets while visiting the park. The type of accommodation used therefore has a clear influence on the magnitude of spending.

The results of this article support the findings of Craggs and Schofield (2006), who indicated that a wide range of variables influence visitor expenditure. Language, age, marital status, the number of times the park has been visited and owning a Wild Card indicated no significant differences between the segments as was indicated in the literature review (see Spotts and Mahoney (1991), Downward and Lumsdon (2004), Saayman et al. (2008b), Saayman and Saayman (2006) and Leones et al. (1998)). The variables that indicated significant differences were province of origin, group size, the number of days spent at the park and the type of accommodation. These variables can be used to distinguish between the two different expenditure groups at the Tsitsikamma National Park, as indicated in Table 6 below. 
Table 6: Segmentation categories: High and Low spenders

\begin{tabular}{|l|c|c|}
\hline Variables & High spenders & Low spenders \\
\hline Province of origin & Gauteng & Western Cape \\
Group size & 1 person & 2 persons \\
Length of stay & 3 days & 2 days \\
Accommodation preference & Chalets & Camping \\
\hline
\end{tabular}

Based on the results as indicated in Table 3, the following findings can be reported. Firstly, only two distinct markets were identified compared to research done by Saayman et al. (2007) in the Kruger National Park, where three distinct markets (high, medium and low) were identified. The reason for this is most probably rooted in the number of visitors (both local and overseas visitors) visiting the Kruger National Park as well as the size of the operation and the variety of activities on offer compared to the Tsitsikamma National Park. Secondly, visitors to the Tsitsikamma National Park who travel from Gauteng tend to be high spenders, whereas visitors who originate from the Western Cape tend be low spenders. These results support the findings of Saayman et al. (2007) who also revealed that high spenders at the Kruger National Park originate from Gauteng and the low spenders from the Western Cape. Tourists from the Western Cape seem to prefer camping and they tend to stay for shorter periods compared to tourists from Gauteng who prefer chalets and stay for longer periods. Thirdly, length of stay has a positive impact on expenditure, thereby supporting research done by Spotts and Mahoney (1991), Downward and Lumsdon (2004), Pouta et al. (2006), Saayman et al. (2007), Saayman et al. (2008) and Mehmetoglu (2007). However, it contradicts the findings of Leones et al. (1998) who found, in the research they conducted on tourists tracking in nature areas, that shorter trips had a positive impact on expenditure. Fourthly, high spenders tend to travel in smaller groups compared the low spenders who travel in larger groups, which is again consistent with research conducted by Saayman et al. (2007). An explanation for this could be that larger groups share the costs, which makes the trip cheaper per person. Lastly, high spenders at the Tsitsikamma National Park prefer to stay in chalets compared to the low spenders who favour camping.

\section{IMPLICATIONS AND RECOMMENDATIONS}

Table 4 indicates that there is a significant difference between the high spenders at the park compared to the low spenders, and therefore the marketers of the Tsitsikamma National Park can follow either a customised (niche) marketing strategy or a multi-segmented approach to select the target market. If marketers want to target tourists who spend more at the park, the high-spending segment would be the preferred choice (customised strategy). This approach will create a greater economic impact, thereby benefiting more people in the surrounding communities. The results are also important from an ecological point of view, since high spenders stay longer and travel in smaller groups compared to low spenders who travel in larger groups and stay at the park for shorter periods. If marketers follow a multi-segmented approach (targeting both the high and low spenders), low spenders have an advantage in the sense that they prefer to travel in larger groups, thereby increasing the number of visitors to the park. It may be advisable for the Tsitsikamma National Park to consider a multi-segmented approach since the low spenders represent the majority of the visitors.

Some significant marketing implications for each segment emerge from the these findings. Firstly, it is clear that, to attract more high spenders, Gauteng should be targeted and, for the low spenders, the Western Cape. Since tourists from Gauteng prefer chalets, these should be one of the drawcards and, for the Western Cape tourists, it should be the camping facilities. The quality and variety of accommodation facilities should also be highlighted in the promotion campaign. Secondly, high spenders should be encouraged to stay longer at the park and this can be achieved by offering more activities e.g. diving, snorkelling, boat rides, dolphin and whale watching, and educational trips. Thirdly, the park should cooperate with other tourism product and service providers within the tourism cluster to market attractions in the area whilst staying at Tsitsikamma National Park to increase visitors' length of stay and spending. Lastly, packages aimed at both the high- and low-expenditure segments that include local attractions could also be an effective way of increasing the length of stay and group size as well as the overall 
spending at the park. Targeting the high as well as the low spenders at the Tsitsikamma National Park is therefore not only viable from a marketing point of view, but also from an economic point of view, since this will assist in ensuring the future profitability and sustainability of the park. From a product development point of view, more chalets should lead to more tourists spending greater amounts of money and it gives park management the opportunity to attract more high spenders (tourists from Gauteng).

\section{CONCLUSION}

The purpose of this article was to apply expenditure-based segmentation to visitors at the Tsitsikamma National Park. Two objectives have been identified - to determine the socio-demographic and behavioural variables that influence spending and, secondly, to make recommendations on how to attract the highspending markets to the park. Even though this type of research has been done for the Kruger National Park, a more innovative approach was followed by using K-clustering, which is also the first time that this approach was followed in determining the high-spending market at the Tsitsikamma National Park. Two distinct markets were identified. These were the high and low spenders where the most significant sociodemographic and behavioural variables that influence spending were province of origin, group size, length of stay and preferred type of accommodation. Interestingly, aspects such as owning a Wild Card (which is a loyalty card) showed no significant difference. The same applies for age, marital status or frequency of visits. Therefore, the results (if one compares this research with that done at the Kruger National Park) confirm that the size of operations and activities available has a dual impact. Firstly, in terms of the number and variety of markets the park or destination can attract and secondly that more available activities lead to increased expenditure. Drawing lessons from this research, it becomes evident that park managers have to deal with the issues raised above if they want to realise the three main objectives of South African national parks as indicated in the introduction. 


\section{REFERENCES}

CROMPTON, J.L. 1979. Motivations for pleasure vacation. Annals of Tourism Research, 6(1):408-424.

DIAZ-PEREZ, F.M., BETHENCOURT-CEJAS, M. \& ALVAREZ-GONZALES, F.M. 2005. The segmentation of Canary Islands tourism markets by expenditure - implications for tourism policy. Tourism Management, 26(6):961-964.

DIBB, S. \& SIMKIN, L. 1996. The Market Segmentation Workbook. Target Marketing for Marketing Managers. Routledge: London and New York. 171 p.

DOWNWARD, P. \& LUMSDON, L. 2004. Tourism Transport and Visitor Spending: A Study in the North York Moors National Park, UK. Journal of Travel Research, 42(4): 415-420.

FAASEN, H. 2006. Synergies between biodiversity conservation and sustainable rural development of adjacent communities: a case study of the Tsitsikamma National Park. Stellenbosch: University of Stellenbosch. (Thesis - Master of Science in conservation ecology.

FRECHTLING, D.C. 2006. An assessment of visitor expenditure methods and models. Journal of Travel Research, 45(1):26-35.

GOKOVALI, U., BAHAR, O. \& KOZAK, M. 2007. Determinants of length of stay: A practical use of survival analysis. Tourism Management, 28:736-746p.

JOHNSON, R.A. \& WICHERN, D.W. 2002. Applied multivariate statistical analysis. Upper Saddle River, NJ: Pearson Prentice Hall. 773p.

KASTENHOLZ, E. 2005. Analysing determinants of visitor spending for the rural tourist market in North Portugal. Tourism Economics, 11(4): 555-569p.

KRUGER, M. 2009. Spending behaviour of visitors to the Klein Karoo National Arts Festival. Potchefstroom: North West University. (Dissertation - MA Tourism.) 66p.

LAESSER, C. \& CROUCH, G.I. 2006. Segmenting markets by travel expenditure patterns: the case of international visitors to Australia. Journal of Travel Research, 44(4):397-406.

LEGOHEREL, P. \& WONG, K.F. 2006. Market segmentation in the tourism industry and consumers' spending. Journal of Travel and Tourism Marketing, 20(2):15-30.

LEONES, J., COLBY, B. \& CRANDALL, K. 1998. Tracking expenditures of the elusive nature tourists to South-eastern Arizona. Journal of Travel Research, 36:56-64.

MEHMETOGLU, M. 2007. Nature-based Tourists: The relationship between their trip expenditures and activities. Journal of Sustainable Tourism, 15(2):200-215.

MOK, C. \& IVERSON, T.J. 2000. Expenditure-based segmentation: Taiwanese tourists to Guam. Tourism Management, 21:299-305.

MYKLETUN, R.J., CROTTS, J.C. \& MYKLETUN, A. 2001. Positioning an island destination in the peripheral area of the Baltics: a flexible approach to market segmentation. Tourism Management, 22(5):493-500.

OBERHOLZER, S., SAAYMAN, M., SAAYMAN, A. \& SLABBERT, E. 2009. The socio-economic impact of Africa's oldest marine park. Part of the $6^{\text {th }}$ International Congress on Coastal and Marine Tourism conference proceedings held on 23-26 June 2009, Nelson Mandela Bay, South Africa. 181-196. 
POUTA, E., NEUVONEN, M. \& SIEVÄNEN, T. 2006. Determinants of Nature Trip Expenditures in Southern Finland - Implications for Nature Tourism Development. Scandinavian Journal of Hospitality and Tourism, 6(2):118-135.

SAAYMAN, A. \& SAAYMAN, M. 2006. Socio-demographics and visiting patterns of arts festivals in South Africa. Event Management, 9(4):211-222.

SAAYMAN, A., SAAYMAN, M. \& NAUDE, W. 2000. The impact of tourists spending in South Africa Spatial implications. (Paper prepared for the Regional Science Association International (RSAI) International Symposium on Regional Development in South Africa, Port Elizabeth Technikon on 25 January 2000. Port Elizabeth. 1-18p.

SAAYMAN, M., FOUCHE, M. \& KRUGER, M. 2008a. Executive summary of research profiles of selected national parks in South Africa. Institute for Tourism and Leisure Studies: Potchefstroom. 69p. (Unpublished.)

SAAYMAN, M., VAN DER MERWE, P. \& PIENAAR, J. 2007. Expenditure-based segmentation of tourists to the Kruger National Park. First conference of the international associations of tourism economics, 25-27 October 2007: Palma de Mallorca, Spain.

SAAYMAN, M., VAN DER MERWE, P. \& PIENAAR, J. 2008b. Expenditure-based segmentation of South African biltong hunters. SA Journal of Wildlife Research. (Accepted).

SANParks. 2008. Tsitsikamma National Park... place of much water. [Web:] http://www.sanparks.org/parks/tsitsikamma/ [Date of access: 23 June 2008].

\section{SOUTH AFRICAN NATIONAL PARKS see SANParks}

SPOTTS, D.M. \& MAHONEY, E.M. 1991. Segmenting visitors to a destination region based on the volume of their expenditures. Business Research Division, 29(4):42-31.

SPSS Inc. 2007. SPSS® 16.0 for Windows, Release 16.0.0, Copyright@ by SPSS inc., Chicago, Illinois. www.spss.com

\section{STATISTICS SOUTH AFRICA see StatsSA}

StatsSA. 2009. Quarterly force survey: Quarter 3 2009. http://www.statsa.gov.za Date of access 15 December 2009.

TONGE, J. \& MOORE, S.A. 2007. Importance-satisfaction analysis for marine park hinterlands: A Western Australia case study. Tourism Management, 28(3):768-776.

WADE, D.J. \& EAGLES, P. 2003. The use of importance-performance analysis and market segmentation for tourism management in parks and protected areas: an application in Tanzania's national parks. Journal of Ecotourism, 2(3):196-212.

\section{WORLD TOURISM ORGANISATION see WTO}

WTO. 2002. Enhancing the Economic Benefits of Tourism for Local Communities and Poverty Alleviation. World Tourism Organisation. 60p. 